Research Article

\title{
Preparation of Carbon-Supported Ternary Nanocatalysts Palladium-Vanadium-Cobalt for Alcohol Electrooxidation
}

\author{
Thanh Thien Co $\mathbb{D}^{1,2}$ Thi Thanh Thao Pham, ${ }^{1}$ Thi Kieu Chinh Pham, ${ }^{1}$ Thi Duyen Diep, ${ }^{1}$ \\ Le Thanh Nguyen Huynh $\mathbb{D}^{1,2}$ and Viet Hai Le $\mathbb{D}^{1,2}$ \\ ${ }^{1}$ University of Science, Ho Chi Minh City, Vietnam \\ ${ }^{2}$ Vietnam National University, Ho Chi Minh City, Vietnam \\ Correspondence should be addressed to Thanh Thien Co; ctthien@hcmus.edu.vn
}

Received 12 April 2020; Revised 6 July 2020; Accepted 13 August 2020; Published 26 August 2020

Academic Editor: Suresh Kannan Balasingam

Copyright (c) 2020 Thanh Thien Co et al. This is an open access article distributed under the Creative Commons Attribution License, which permits unrestricted use, distribution, and reproduction in any medium, provided the original work is properly cited.

\begin{abstract}
Carbon-supported nanocatalysts palladium-vanadium-cobalt (PdVCo) were synthesized via ethylene glycol (EG) reduction reaction and $\mathrm{NaBH}_{4}$-assisted reduction. The electrocatalytic performance for alcohol oxidation in alkaline solutions was investigated. The XRD and EDX results confirmed the incorporation of V and Co with Pd lattice to form the ternary nanocatalysts PdVCo in a single phase. The $\mathrm{NaBH}_{4}$-assisted EG reduction process exhibited highly dispersed nanoparticles with a uniform size, and the electrochemical surface area (ECSA) determined by cyclic voltammetry in $1 \mathrm{M} \mathrm{KOH}$ was also superior. In electrocatalysis performance, the cyclic voltammetry $(\mathrm{CV})$ and chronoamperometry $(\mathrm{CA})$ results presented an excellent electrocatalytic activity and stability of the PdVCo-20EG-20NaBH 4 sample in the alcohol electrooxidation as compared to other synthesized samples with the steady current of $52 \mathrm{~mA} / \mathrm{cm}^{2}$ and $21.9 \mathrm{~mA} / \mathrm{cm}^{2}$ in methanol and ethanol, respectively.
\end{abstract}

\section{Introduction}

The blooming interest in using Direct Alcohol Fuel Cells (DAFCs) as portable and mobile power sources is rooted in their desirable features of relatively small environmental footprint, compact system design, and higher volumetric energy densities compared with existing technologies. [1, 2] DAFC relies on the oxidation of alcohol, such as methanol, ethanol, or glycerol, on a catalyst layer to form carbon dioxide $\left(\mathrm{CO}_{2}\right)$. Water $\left(\mathrm{H}_{2} \mathrm{O}\right)$ is consumed at the anode and produced at the cathode. Hydrogen ions formed during the oxidation of alcohol are transported across the proton exchange membrane to the cathode, where they react with oxygen $\left(\mathrm{O}_{2}\right)$ to produce water. Electrons are transported through an external circuit from the anode to the cathode, providing power to external devices.

Pd-based electrocatalysts are known to achieve better alcohol electrocatalytic oxidation activity than Pt-based ones. [3-6] Moreover, the incorporation between one or multiple transition metals and Pd to design carbon- supported Pd-based bimetallic-alloy [7-14] and trimetallicalloy [15-19] catalysts or surface modification of Pd-based catalyst, such as PdCu@C [12, 20, 21], PdCo@C [7, 22, 23], PdAg@C [10], and PdNi@C $[8,24]$, not only promotes the electrochemical activity and stability but also proposes an efficient way to reduce cost at the same time due to their adjusted d-band electronic structure and surface atom rearrangement. [19, 25, 26] Rostami and coworkers [27] reported the enhancement of ethanol electrooxidation of ternary $\mathrm{PdCuNi}$ catalyst when $\mathrm{Ni}$ was incorporated; the addition of $\mathrm{Ni}$ accelerated the removal of adsorbed carbonaceous intermediate species during ethanol oxidation. Huang and colleagues [28] prepared a core-shell ternary $\mathrm{PdCuBi} / \mathrm{C}$ catalyst that exhibited an excellent performance toward ethylene glycol oxidation.

Ethylene glycol reduction is common process for the preparation of metal nanoparticles, but this process needs to be assisted by high temperature or microwave irradiation to improve the reduced performance. $[6,15,28]$ However, $\mathrm{NaBH}_{4}$ is considered as a force reducing agent which can 
reduce metallic ions at room temperature, and the disadvantage of $\mathrm{NaBH}_{4}$ process is the formation of irregular particle size. [29-33] As a consequence, the combination process of ethylene glycol (EG) and $\mathrm{NaBH}_{4}$ can get better reduction to prepare the nanoparticles.

In this work, we prepared the carbon-supported ternary nanocatalysts palladium-vanadium-cobalt (PdVCo) by ethylene glycol reduction process and, the $\mathrm{NaBH}_{4}$-assisted reduction was also considered. The nanocatalysts PdVCo showed a comparable alcohol electrocatalytic oxidation activity and stability as compared to the original Pd catalyst.

\section{Experimental}

2.1. Materials. Analytical grade $\mathrm{PdCl}_{2}$ (ReagentPlus ${ }^{\circledR}, 99 \%$, Sigma Aldrich), $\mathrm{Co}\left(\mathrm{NO}_{3}\right)_{2} \cdot 6 \mathrm{H}_{2} \mathrm{O}$ (Sigma Aldrich, >99.9\%), Vulcan XC-72R (Cabot, USA), polytetrafluoroethylene solution (PTFE, Sigma Aldrich, 65\% in water), $\mathrm{V}_{2} \mathrm{O}_{5}$ (Merck, 99.5\%), $\mathrm{NaBH}_{4}$ (Merck, 99.5\%), and ethylene glycol (EG, Merck, 99.5\%) were used without further purification. All the aqueous solutions were prepared with deionized water (DI water, $18.2 \mathrm{M} \Omega \mathrm{cm}$ ) in the whole experiment.

2.2. Carbon-Supported Nanocatalyst Preparation. Carbon Vulcan powder underwent two-step treatment to eliminate the metal traces. In the acid treatment, the carbon powder was soaked in $1 \mathrm{M} \mathrm{HNO}_{3}$ for 10 hours, coupled with ultrasonic irradiation for 15 minutes per hour; the powder was washed several times with DI water and dried at $70^{\circ} \mathrm{C}$ overnight. Next, the carbon powder was soaked in $1 \mathrm{M}$ $\mathrm{NaOH}$ for 1 hour, washed with DI water, and dried at $70^{\circ} \mathrm{C}$ overnight. After that, the powder was heated at $200^{\circ} \mathrm{C}$ for 2 hours to obtain the pretreated carbon powder.

$0.8850 \mathrm{~g} \mathrm{PdCl}_{2}$ was dissolved in $100 \mathrm{~mL} 0.01 \mathrm{M} \mathrm{HCl}$, $0.91000 \mathrm{~g} \mathrm{~V}_{2} \mathrm{O}_{5}$ was dissolved in $100 \mathrm{~mL} 0.15 \mathrm{M} \mathrm{NaOH}$, and $0.915 \mathrm{~g} \mathrm{Co}\left(\mathrm{NO}_{3}\right)_{2} \cdot 6 \mathrm{H}_{2} \mathrm{O}$ was dissolved in $100 \mathrm{~mL}$ DI water to obtain precursor solution $0.05 \mathrm{M} \mathrm{H}_{2} \mathrm{PdCl}_{4}, 0.05 \mathrm{M} \mathrm{Na}_{3} \mathrm{VO}_{4}$, and $0.05 \mathrm{M} \mathrm{Co}\left(\mathrm{NO}_{3}\right)_{2}$, respectively. The reduction agents were EG and $0.01 \mathrm{M} \mathrm{NaBH}_{4}$.

The carbon-supported nanocatalysts PdVCo at $20 \mathrm{wt} \%$ were prepared by the polyol reduction process. The precursor's solutions $\mathrm{H}_{2} \mathrm{PdCl}_{4}, \mathrm{Na}_{2} \mathrm{VO}_{3}$, and $\mathrm{Co}\left(\mathrm{NO}_{3}\right)_{2}$ with the stoichiometry $\mathrm{Pd}: \mathrm{V}:$ Co ratio of $1: 1: 1$ were stirred in an ultrasonic condition; then, $100 \mathrm{mg}$ pretreated Vulcan XC$72 \mathrm{R}$ carbon powder was added, and the mixture was ultrasonicated for 30 minutes. The reduction agents were dropped into the mixture, following four samples: (i) $15 \mathrm{~mL}$ EG, (ii) $20 \mathrm{~mL}$ EG, (iii) $15 \mathrm{~mL} \mathrm{EG}+20 \mathrm{~mL} \mathrm{NaBH}_{4}$, and (iv) $20 \mathrm{~mL}$ EG $+20 \mathrm{~mL} \mathrm{NaBH}_{4}$. The products were filtered, washed with DI water several times, and dried in an oven at $120^{\circ} \mathrm{C}$ for 2 hours. We then denoted the respective nanocatalyst samples: (i) PdVCo-15EG; (ii) PdVCo-20EG; (iii) PdVCo-15EG-20NaBH 4 ; and (iv) PdVCo-20EG-20NaBH 4 .

The structure was characterized by X-ray diffraction by using a D8-Advance Diffractometer (Bruker) with $\mathrm{Cu} \mathrm{K \alpha}$ radiation $(\lambda=1.5406 \AA)$. The size and morphological features were analyzed by SEM with energy-dispersive X-ray (EDX) detector using a Hitachi S-4800 instrument, and transmission electron microscopy (TEM) was performed using a JEOL JEM 1400 microscope at $120 \mathrm{kV}$. Brunauer-Emmett-Teller specific surface area $\left(\mathrm{S}_{\mathrm{BET}}\right)$ was determined by nitrogen adsorption measurement (Quantachrome Autosorb 1C) with an out-gas process at $200^{\circ} \mathrm{C}$ for 2 hours.

2.3. Electrochemical Measurements. All the electrochemical measurements were carried out at room temperature under nitrogen atmosphere on potentiostat/galvanostat PGSTAT320N (Metrohm, AG) apparatus with a threeelectrode cell, including a glassy carbon electrode (GCE, $3 \mathrm{~mm}$ in diameter) as working electrode, a platinum wire as counter electrode, and a $\mathrm{Ag} / \mathrm{AgCl}$ in $3.5 \mathrm{M} \mathrm{KCl}$ electrode as reference electrode. To prepare the working electrode, $2.5 \mathrm{mg}$ nanocatalysts PdVCo were put into $1.0 \mathrm{~mL}$ ethanol and $25 \mu \mathrm{l}$ PTFE solution; the mixture was then ultrasonicated for 1 hour to obtain a homogeneous suspension. $75 \mu \mathrm{l}$ of suspension was dropped on GCE and dried at $40^{\circ} \mathrm{C}$ in 1 hour. The electrocatalytic behavior of synthesized nanocatalysts was studied by cyclic voltammetry (CV) and chronoamperometry (CA). In order to determine the electrochemical surface areas (ECSAs) of the nanocatalysts, the $\mathrm{CV}$ measurements were carried out in a solution of $1 \mathrm{M}$ $\mathrm{KOH}$ at a scan rate of $50 \mathrm{mV} / \mathrm{s}$ from $-1 \mathrm{~V}$ to $0.5 \mathrm{~V}$. For the alcohol oxidation electroactivity, the $\mathrm{CV}$ measurements in a solution of $1 \mathrm{M} \mathrm{CH}_{3} \mathrm{OH}+1 \mathrm{M} \mathrm{KOH}$ and $1 \mathrm{M} \mathrm{C}_{2} \mathrm{H}_{5} \mathrm{OH}+1 \mathrm{M}$ $\mathrm{KOH}$ were conducted from $-0.8 \mathrm{~V}$ to $0.3 \mathrm{~V}$ with a scan rate of $50 \mathrm{mV} / \mathrm{s}$. CA measurements were performed in the same alcohol-contained $\mathrm{KOH}$ solution at an applied voltage of $-0.130 \mathrm{~V}$ or $-0.150 \mathrm{~V}$ for an hour.

\section{Results and Discussion}

3.1. Physiochemical Characterization. Figure 1 shows the typically XRD pattern of carbon-supported nanocatalysts PdVCo with the metal loading of $20 \mathrm{wt} \%$ (sample PdVCo20EG- $\mathrm{NaBH}_{4}$ ). The characteristic peaks of face-center cubic crystalline Pd (JCPDS Card 00-005-0681) are observed with the planes (111), (200), and (220), suggesting the singlephase structure for all nanocatalysts. Compared to the original phase $\operatorname{Pd}(a=3.8971 \AA)$, the characteristic peaks of PdVCo-20EG-NaBH ${ }_{4}$ quietly shift toward higher $2 \theta$, reflecting the incorporation of $\mathrm{V}$ and Co into the Pd lattice to form a ternary-alloy phase PdVCo. Moreover, the cubic lattice parameter of PdVCo-20EG- $\mathrm{NaBH}_{4}$ is slightly decreased to $a=3.8618 \AA$ (detailed in Table S1) due to the smaller atom radius of $\mathrm{Co}$ and $\mathrm{V}$. The broadening of the diffraction peaks is considered as the nanocrystalline characteristic of nanocatalysts PdVCo. The average crystallite size is calculated from the full width of the half maximum (FWHM) of highest intensity peak (111) through Debye-Scherrer equation (1) $[13,20]$ :

$$
d_{h k l}=\frac{k \lambda}{\beta \cos \theta},
$$

where $d_{h k l}$ is the average crystallite size; $k$ is the constant depending on the crystallite shape (0.9); $\lambda$ is the wavelength 


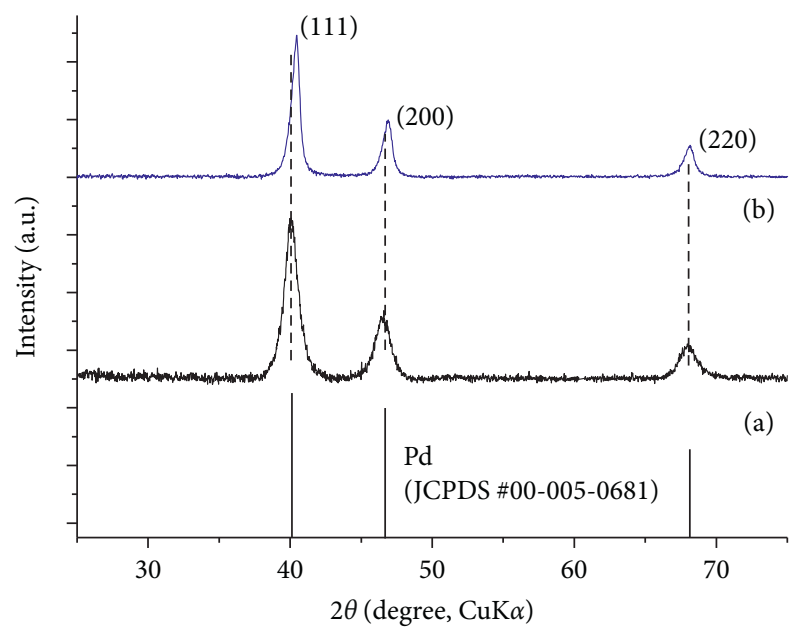

FIgURE 1: XRD patterns of nanocatalysts: (a) Pd-20EG-20NaBH 4 and (b) PdVCo-20EG-20NaBH 4 .

of copper K $\alpha$ X-ray radiation (1.5406 $\AA$ ); $\beta$ is the FWHM (in radian) of the most intense peak (in radian) and is determined by X'Pert HighScore Plus software; and $\theta$ is the diffraction angle. The average crystallite sizes of nanocatalysts PdVCo are gathered in Table S1. We observed that the crystallite sizes are around 5-6 nm. Although no Co and $\mathrm{V}$ peaks can be seen in XRD patterns, the EDX spectrum (Figure 2) of nanocatalysts indicates clearly the presence of the elements $\mathrm{V}$ and Co in ternary alloy; the mass ratios of $\mathrm{Pd}: \mathrm{V}$ :Co are shown in Table 1. The Co-content and especially $\mathrm{V}$-content in two $\mathrm{NaBH}_{4}$-assisted reduction samples are higher than those in the other samples; the atomic ratios of Pd: V:Co in PdVCo-15EG-NaBH4 and PdVCo-20EG$\mathrm{NaBH} 4$ are $1: 0.35: 0.59$ and $1: 0.55: 0.86$, respectively. The results revealed the beneficial support of $\mathrm{NaBH}_{4}$ for trimetallic-alloy reduction.

Figure 3 shows the TEM images and particle size distribution of the nanocatalysts. The synthesized nanoparticles PdVCo have a small and uniform size and are well dispersed on the carbon surface with a narrow particle size distribution of $3 \mathrm{~nm}$ to $9 \mathrm{~nm}$. In case of EG reduction agent, the nanoparticles are found with an average particle diameter of $6.8 \mathrm{~nm}$, and the particle size larger $6 \mathrm{~nm}$ occupied more than $50 \%$. Rather, in case of $\mathrm{NaBH}_{4}$-assisted reduction agents, the nanoparticles look smaller; the major particle size lies in range $5 \mathrm{~nm}$ to $7 \mathrm{~nm}$. The $\mathrm{NaBH}_{4}$ assisted in the polyol reduction process that leads to little smaller and more uniformly sized nanoparticles. [29] Moreover, the incorporation of $\mathrm{V}$ and Co also supports a decrease of catalyst particle size and the modified-surface structure of Pd that leads to the surfaceadsorbed species, and the electronic effect contributes to the alcohol electrooxidation on the $\mathrm{Pd}$ nanoparticles. $[31,34,35]$.

The BET surface area $\left(\mathrm{S}_{\mathrm{BET}}\right)$ of nanocatalysts was evaluated by $\mathrm{N}_{2}$ absorption and is detailed in Table 2 . The increase of $S_{\mathrm{BET}}$, which was caused by the increase of EG, decreased the nanoparticle size. The smaller nanoparticle size can be favorable for the higher ECSA and catalytic activity for alcohol electrochemical reaction.
3.2. Electrochemical Behaviors. In order to estimate the electrochemical surface area (ECSA), the CV measurement was performed in $1 \mathrm{M} \mathrm{KOH}$ at a scan rate of $50 \mathrm{mV} / \mathrm{s}$ (Figure 4). Commonly, the CV curve of Pd-based nanocatalysts in $\mathrm{KOH}$ media presents three regions: (i) a potential region lower than $-0.7 \mathrm{~V}$ assigned to the oxidation of the absorbed and the absorption of hydrogen from the catalyst surface; (ii) a potential region from -0.7 to $-0.2 \mathrm{~V}$ corresponding to the formation of palladium hydroxides; and (iii) a potential region from -0.2 to $0.4 \mathrm{~V}$ relating to the palladium oxidation. For the reverse scan, the reduction of palladium oxide ( $\mathrm{Pd}-\mathrm{O}$ layers) to $\mathrm{Pd}^{0}$ appeared around -0.35 V. $[10,27,33]$ The ECSA can be estimated by PdO reduction peak in CVs according to the following equation [27]:

$$
\mathrm{ECSA}=\frac{Q_{S} \times 10^{-4}}{\left(Q_{C} \times m\right)}
$$

where $Q_{s}$ is the total charge $(\mathrm{mC})$ determined by integrating current peak of palladium oxide reduction, $Q_{C}$ is the charge needed for the reduction of $\mathrm{PdO}$ monolayer, and $m$ is the $\mathrm{Pd}$ loading in mg. The ECSA was also determined by the Coulombic charge corresponding to the oxide reduction peak at a negative potential of $-0.36 \mathrm{~V}$ (vs. $\mathrm{Ag} / \mathrm{AgCl}$ ) in Figure 4 . The calculated ECSAs are detailed in Table 3, The PdVCo-15EG-20NaBH $4\left(282 \mathrm{~cm}^{2} / \mathrm{mg}\right.$ with $Q_{C}=0.581 \mathrm{mC} /$ $\left.\mathrm{cm}^{2}\right)$ and PdVCo-20EG-20NaBH 4 (375 $\mathrm{cm}^{2} / \mathrm{mg}$ with $Q_{C}=0.741 \mathrm{mC} / \mathrm{cm}^{2}$ ) catalysts exhibit higher ECSAs than the EG-reduced catalyst.

The alcohol electrooxidation was performed by cyclic voltammetry on the nanocatalysts PdVCo in alkaline medium. The cyclic voltammograms are shown in Figures 5 and 6. Although mechanisms of electrooxidation of methanol and ethanol are different, their cyclic voltammograms exhibit the same motif with two well-defined peaks in each curve. [2] In the forward scan, the oxidation peak can be assigned to the oxidation of freshly chemisorbed species coming from methanol or ethanol adsorption. The oxidation peak in the reverse scan associated with the removal of 


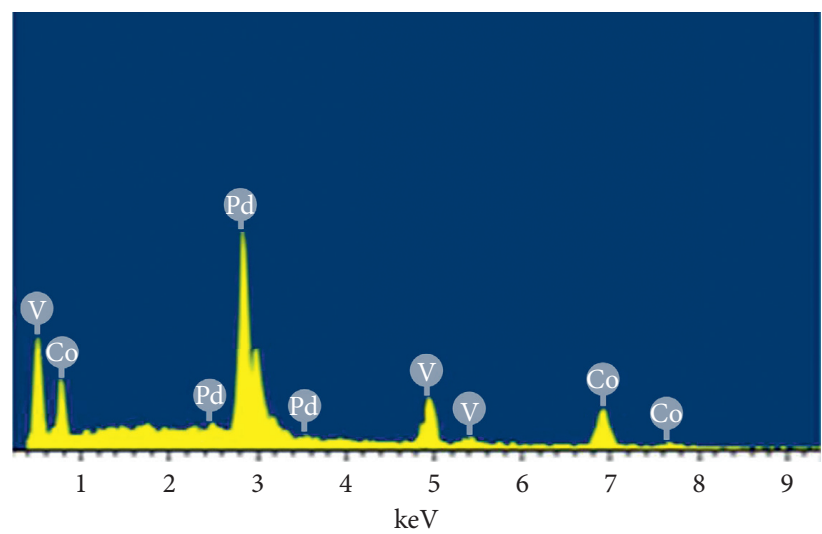

(a)

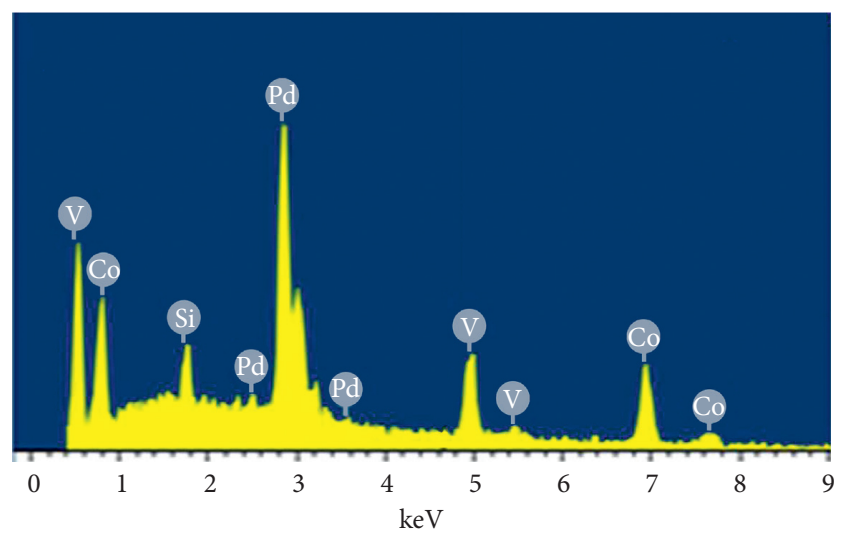

(b)

Figure 2: EDX spectra of nanocatalysts: (a) PdVCo-15EG-20NaBH ${ }_{4}$ and (b) PdVCo-20EG-20NaBH . $^{2}$

TABLe 1: Ratio of Pd: V:Co in nanocatalysts.

\begin{tabular}{|c|c|c|c|}
\hline Sample & Element & Mass $\%$ & Ratio Pd: V:Co \\
\hline \multirow{3}{*}{ PdVCo-15EG } & $\mathrm{Pd}$ & 76.28 & \multirow{3}{*}{$1: 0.19: 0.42$} \\
\hline & $\mathrm{V}$ & 8.38 & \\
\hline & Co & 15.37 & \\
\hline \multirow{3}{*}{ PdVCo-20EG } & $\mathrm{Pd}$ & 70.08 & \multirow{3}{*}{$1: 0.23: 0.61$} \\
\hline & $\mathrm{V}$ & 9.15 & \\
\hline & Co & 20.77 & \\
\hline \multirow{3}{*}{ PdVCo-15EG-20NaBH 4} & $\mathrm{Pd}$ & 67.65 & \multirow{3}{*}{$1: 0.35: 0.59$} \\
\hline & $\mathrm{V}$ & 13.20 & \\
\hline & Co & 19.15 & \\
\hline \multirow{3}{*}{ PdVCo-20EG-20NaBH 4} & $\mathrm{Pd}$ & 58.19 & \multirow{3}{*}{$1: 0.55: 0.86$} \\
\hline & $\mathrm{V}$ & 17.77 & \\
\hline & Co & 24.06 & \\
\hline
\end{tabular}

carbonaceous species (mostly in the form of linearly bonded $\mathrm{Pd}=\mathrm{C}=\mathrm{O}$ ) is not completely oxidized in the forward scan compared to the oxidation of freshly chemisorbed species. [36-40] The magnitude of the peak current in the forward scan indicates the electrocatalytic activity of the electrocatalysts for alcohol oxidation. Furthermore, the ratio of the forward anodic peak current density $\left(I_{f}\right)$ to the reverse anodic peak current density $\left(I_{b}\right), I_{f} / I_{b}$, is used to determine the catalyst's tolerance to the intermediate carbonaceous species accumulated on the electrode surface. [41, 42] A higher ratio of $I_{f} / I_{b}$ promotes a better electrocatalytic activity and resistance to $\mathrm{CO}$ poisoning on the electrode surface. The potential and current density of the alcohol oxidation peak in the forward scan and $I_{f} / I_{b}$ ratio are detailed in Table 3.

Figure 5 displays the cyclic voltammetry on nanocatalysts PdVCo at a scan rate of $50 \mathrm{mV} / \mathrm{s}$ in the solution of $1 \mathrm{M} \mathrm{CH} \mathrm{CH}_{3} \mathrm{OH}+1 \mathrm{M} \mathrm{KOH}$. We observed that the current density became higher with the increase of reduction agent. Particularly, the highest current density $\left(86.7 \mathrm{~mA} / \mathrm{cm}^{2}\right)$ can be found in the mixture of reduction agent (sample PdVCo20EG-20NaBH 4 ), which can be attributed to the fact that the $\mathrm{NaBH}_{4}$ assisted in the EG reduction process with highly dispersed nanoparticles with a uniform size (4-5 nm) and the highest electrochemical surface area. [29] Moreover, the $I_{f} / I_{b}$ ratio varies among the PdVCo nanocatalysts. For EG reduction agent, the ratios are almost 2.5; for $\mathrm{NaBH}_{4}$ assisted reduction, they increased significantly. The ratios for PdVCo-15EG-20NaBH 4 and PdVCo-20EG-20NaBH 4 are 2.82 and 2.98, respectively. On the other hand, the onset potential of PdVCo nanocatalysts looked more negative than those of sample Pd-20EG-20NaBH 4 (Figure S3 and Table S2). The more negative onset potential can suggest the enhancement of Co tolerance and increase of electrocatalytic performance as well as stability. $[31,33,43]$ In sum, the data from $\mathrm{CV}$ measurements indicated that the nanocatalyst PdVCo-20EG- $\mathrm{NaBH}_{4}$ exhibited superior catalytic activity for methanol oxidation.

The CVs of the nanocatalysts in a solution of $1 \mathrm{M}$ $\mathrm{KOH}+1 \mathrm{M} \mathrm{C}_{2} \mathrm{H}_{5} \mathrm{OH}$ are shown in Figure 6. Two well-defined oxidation peaks can be observed in the five $\mathrm{CV}$ curves. The PdVCo-20EG-20NaBH 4 catalyst shows the best catalytic activity and poisoning tolerance among the five catalysts, as evidenced by its largest peak current and $i_{f} i_{b}$ ratio. It is apparent that the size effect promotes the higher catalytic activity of nanocatalysts PdVCo for the alcohol electrooxidation.

In order to evaluate the long-term activity of the alcohol oxidation reaction on nanocatalysts $\mathrm{PdVCo}$, we performed the CA measurements for $3600 \mathrm{~s}$ at $-0.130 \mathrm{~V}$ (vs. $\mathrm{Ag} / \mathrm{AgCl}$ ) in solution of $1 \mathrm{M} \mathrm{KOH}+1 \mathrm{M} \mathrm{CH}_{3} \mathrm{OH}$ (shown in Figure 7) 

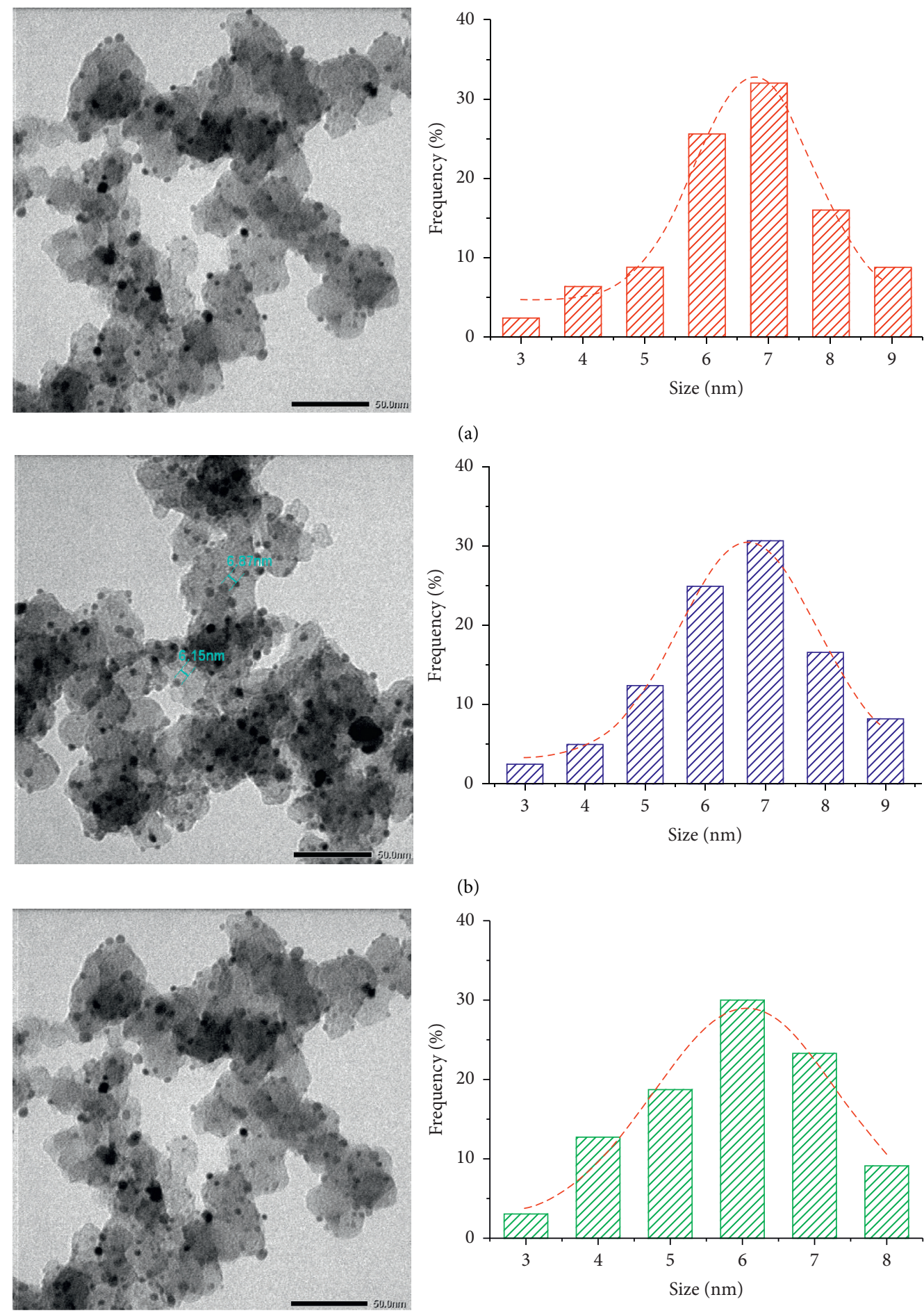

(c)

Figure 3: Continued. 

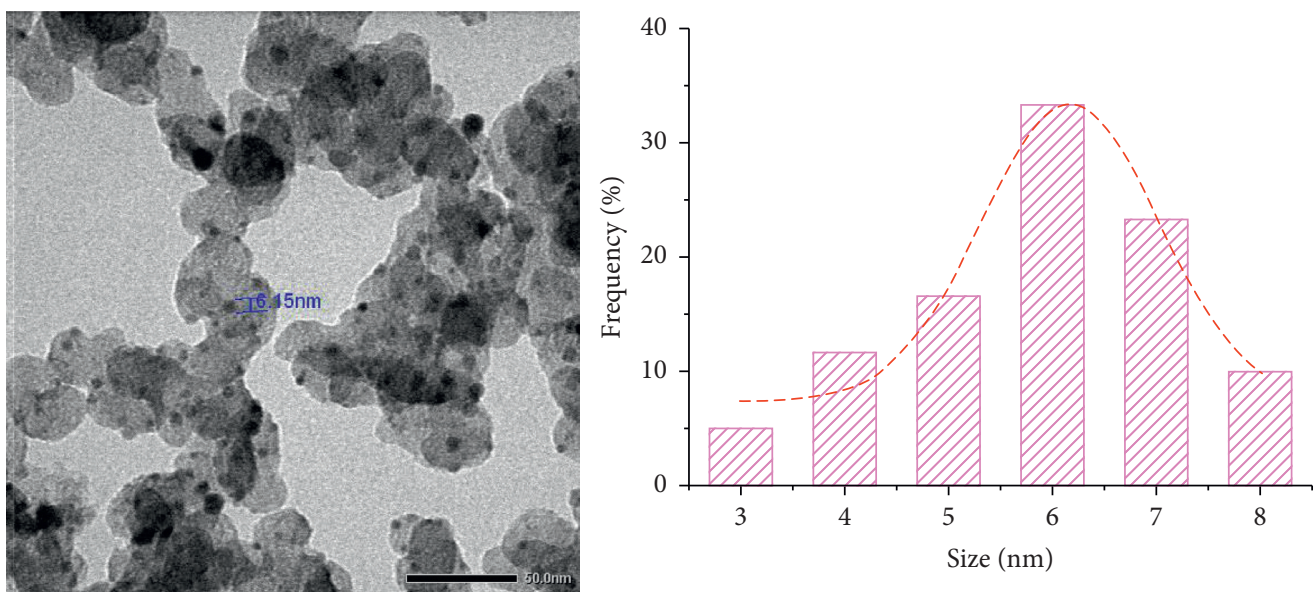

(d)

Figure 3: TEM images and particle size distribution nanocatalysts: (a) PdVCo-15EG; (b) PdVCo-20EG; (c) PdVCo-15EG-20NaBH 4 ; and (d) PdVCo-20EG-20NaBH 4 .

TABLE 2: Specific area and particle size distribution of nano-PdVCo catalysts.

\begin{tabular}{lccc}
\hline Sample & $\mathrm{S}_{\text {BET }}\left(\mathrm{m}^{2} / \mathrm{g}\right)$ & Particle size average $(\mathrm{nm})$ & \% of particle size larger than $6 \mathrm{~nm}$ \\
\hline PdVCo-15EG & 69.6 & 6.76 & 56.8 \\
PdVCo-20EG & 73.6 & 6.72 & 54.1 \\
PdVCo-15EG-20NaBH & 73.4 & 6.10 & 31.7 \\
PdVCo-20EG-20NaBH & 75.2 & 6.14 & 33.2 \\
\hline
\end{tabular}

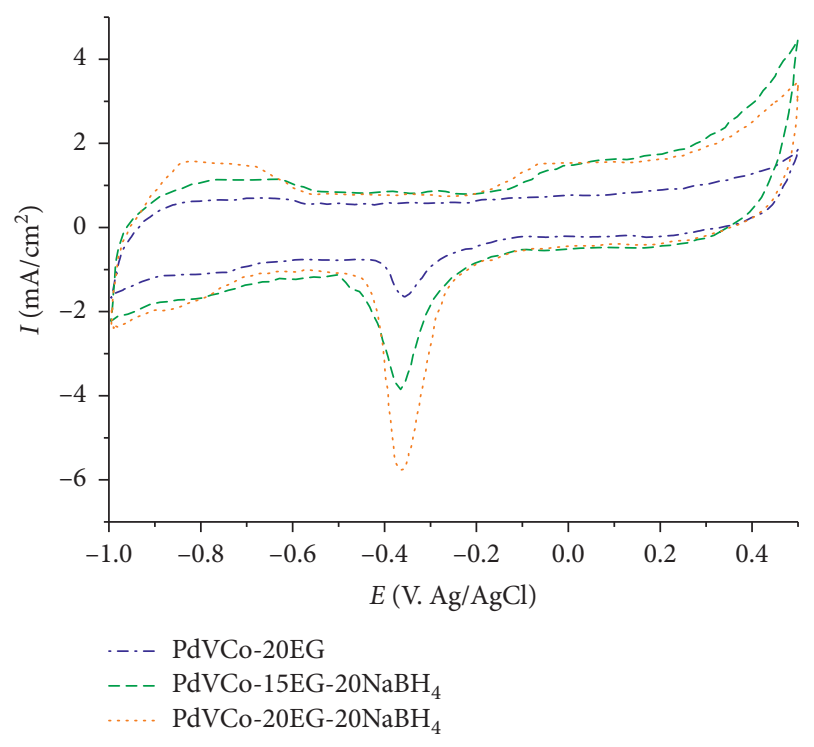

Figure 4: CVs of nanocatalysts PdVCo in $1 \mathrm{M} \mathrm{KOH}$ at a scan rate of $50 \mathrm{mV} / \mathrm{s}$.

TABLE 3: Electrochemical parameters from alcohol oxidation of nanocatalysts PdVCo.

\begin{tabular}{|c|c|c|c|c|c|c|c|c|c|}
\hline \multirow{2}{*}{ Sample } & \multirow{2}{*}{ ECSA $\left(\mathrm{cm}^{2} / \mathrm{mg}\right)$} & \multicolumn{4}{|c|}{$\mathrm{CH}_{3} \mathrm{OH}$} & \multicolumn{4}{|c|}{$\mathrm{C}_{2} \mathrm{H}_{5} \mathrm{OH}$} \\
\hline & & $E(\mathrm{~V})$ & $I_{f}\left(\mathrm{~mA} / \mathrm{cm}^{2}\right)$ & $I_{b}\left(\mathrm{~mA} / \mathrm{cm}^{2}\right)$ & $I_{f} / I_{b}$ & $E(\mathrm{~V})$ & $I_{f}\left(\mathrm{~mA} / \mathrm{cm}^{2}\right)$ & $I_{b}\left(\mathrm{~mA} / \mathrm{cm}^{2}\right)$ & $I_{f} / I_{b}$ \\
\hline PdVCo-15EG & 128 & -0.130 & 60.0 & 25.5 & 2.35 & -0.153 & 23.4 & 32.5 & 0.72 \\
\hline PdVCo-20EG & 137 & -0.124 & 70.6 & 28.4 & 2.49 & -0.177 & 33.6 & 49.3 & 0.67 \\
\hline PdVCo-15EG-20NaBH 4 & 282 & -0.125 & 81.8 & 29.0 & 2.82 & -0.162 & 44.5 & 55.5 & 0.80 \\
\hline PdVCo-20EG-20NaBH & 375 & -0.100 & 86.7 & 29.0 & 2.98 & -0.105 & 56.1 & 75.3 & 0.75 \\
\hline
\end{tabular}




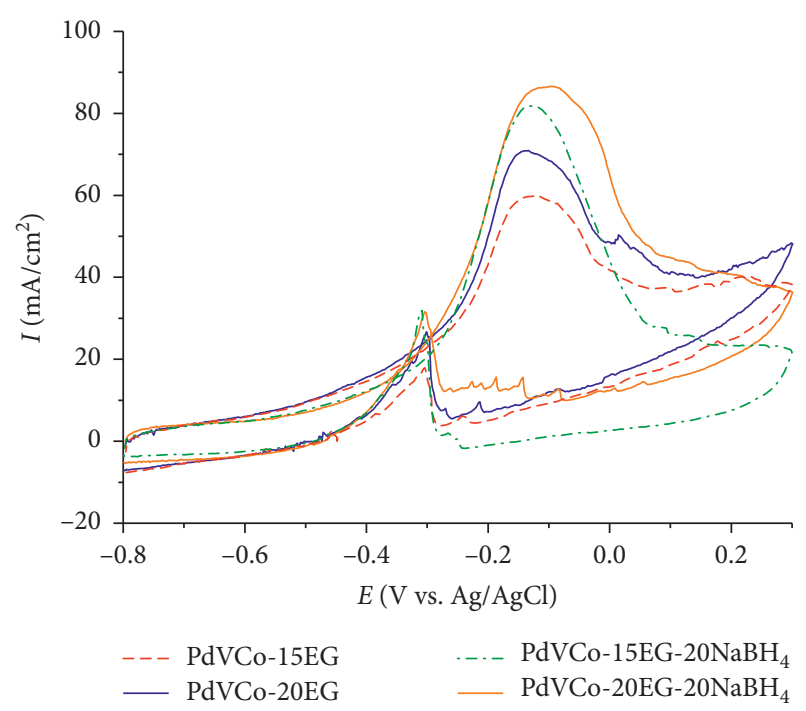

Figure 5: CVs of methanol electrooxidation on nanocatalysts PdVCo in a solution of $1 \mathrm{M} \mathrm{KOH}+1 \mathrm{M} \mathrm{CH}_{3} \mathrm{OH}$.

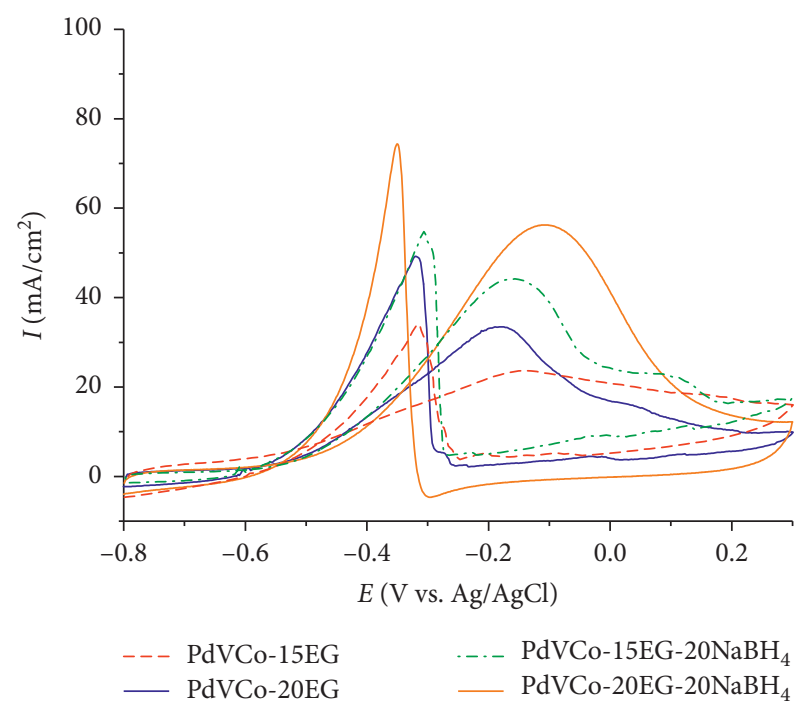

FIGURE 6: CVs of ethanol electrooxidation on nanocatalysts PdVCo in a solution of $1 \mathrm{M} \mathrm{KOH}+1 \mathrm{M} \mathrm{C}_{2} \mathrm{H}_{5} \mathrm{OH}$.

and at $-0.150 \mathrm{~V}$ (vs. $\mathrm{Ag} / \mathrm{AgCl}$ ) in solution of $1 \mathrm{M} \mathrm{KOH}+1 \mathrm{M}$ $\mathrm{C}_{2} \mathrm{H}_{5} \mathrm{OH}$ (shown in Figure 8), respectively. In general, all CA curves present a gradual decline in current density that results from the poisoning of the electrocatalysts, such as the formation of oxides or hydroxides of $\mathrm{Pd}$ and other poisoning intermediates adsorbed on the electrocatalysts during alcohol electrooxidation. [44] It is clear that the current densities on the PdVCo-15EG-20NaBH 4 and PdVCo-20EG$20 \mathrm{NaBH}_{4}$ catalysts are higher than those of all CA measurements.

In methanol solution, the current densities remain about 49 and $52 \mathrm{~mA} / \mathrm{cm}^{2}$ on PdVCo-15EG-20NaBH ${ }_{4}$ and PdVCo20EG-20NaBH 4 , respectively, compared with the other catalysts. Likewise, in an ethanol solution, the PdVCo-20EG$20 \mathrm{NaBH}_{4}$ catalyst exhibits excellent stability. The steady

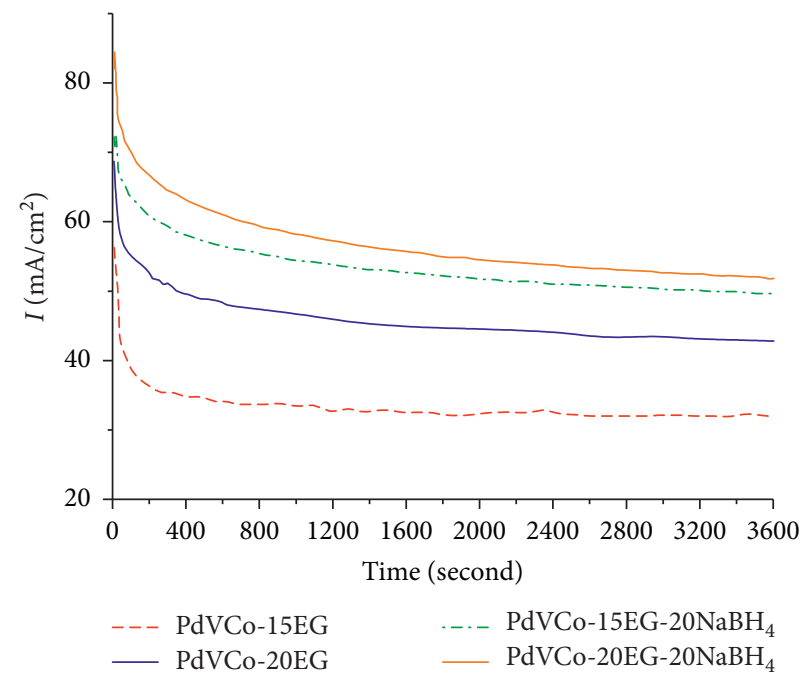

Figure 7: CA curves of nanocatalysts PdVCo recorded at $-0.130 \mathrm{~V}$ in a solution of $1 \mathrm{M} \mathrm{KOH}+1 \mathrm{M} \mathrm{CH}_{3} \mathrm{OH}$.

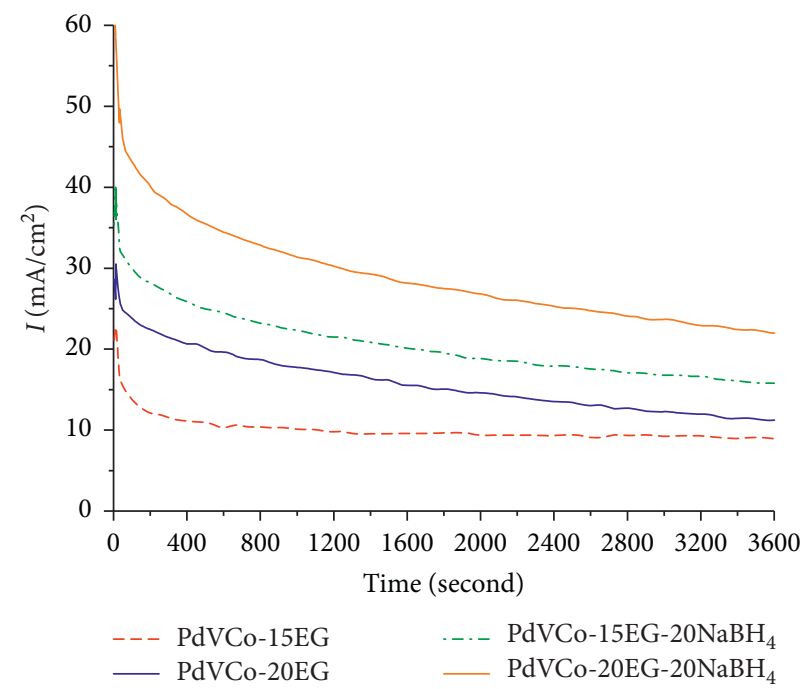

FIgURE 8: CA curves of nanocatalysts PdVCo recorded at $-0.150 \mathrm{~V}$ in a solution of $1 \mathrm{M} \mathrm{KOH}+1 \mathrm{M} \mathrm{C}_{2} \mathrm{H}_{5} \mathrm{OH}$.

current densities are 8.9 and $11.5 \mathrm{~mA} / \mathrm{cm}^{2}$ on PdVCo-15EG and PdVCo-20EG catalysts, respectively, while the steady current on PdVCo-20EG-20NaBH 4 is about $21.9 \mathrm{~mA} / \mathrm{cm}^{2}$. PdVCo-20EG-20NaBH 4 possesses the highest activity in the steady-state region for the oxidation of methanol or ethanol.

\section{Conclusion}

The ternary-alloy nanocatalysts PdVCo were successfully prepared by EG reduction, and the atoms $\mathrm{V}$ and Co were incorporated into Pd lattice to form a single phase. Moreover, the $\mathrm{NaBH}_{4}$ assisted not only in enhancing V-content and Co-content but also in slightly decreasing nanoparticle size, which led to a better electrocatalysis performance for alcohol oxidation. The PdVCo-20EG-20NaBH 4 exhibited superior catalytic activity and stability as compared to the 
other synthesized samples with the steady current of $52 \mathrm{~mA}$ / $\mathrm{cm}^{2}$ in methanol and $21.9 \mathrm{~mA} / \mathrm{cm}^{2}$ in ethanol.

\section{Data Availability}

The data used to support the findings of this study are included within the supplementary information files.

\section{Conflicts of Interest}

The authors declare that they have no conflicts of interest regarding the publication of this paper.

\section{Acknowledgments}

This research was supported by Vietnam National University Ho Chi Minh City (VNU-HCM) under grant no. C2019-18-13.

\section{Supplementary Materials}

Figure S1: XRD patterns of nanocatalysts (a) PdVCo-15EG, (b) PdVCo-20EG, and (c) PdVCo-15EG-20NaBH4. Figure S2: TEM images and particle size distribution of sample Pd20EG-20NaBH4. Figure S3. CVs of nanocatalysts Pd-20EG$\mathrm{NaBH} 4$ in a solution of (a) $1 \mathrm{M} \mathrm{KOH}+1 \mathrm{M} \mathrm{CH}_{3} \mathrm{OH}\left(I_{f} f\right.$ $\left.I_{b}=2.60\right)$ and (b) $1 \mathrm{M} \mathrm{KOH}+1 \mathrm{M} \mathrm{C}_{2} \mathrm{H}_{5} \mathrm{OH}\left(I_{f} / I_{b}=0.63\right)$. Table S1: Average crystallite size of nanocatalysts. Table S2. Onset potential ( $\mathrm{V}$ vs. $\mathrm{Ag} / \mathrm{AgCl}$ ) of nanocatalysts in a solution of $1 \mathrm{M} \mathrm{KOH}+1 \mathrm{M} \mathrm{CH}_{3} \mathrm{OH}$ and $1 \mathrm{M} \mathrm{KOH}+1 \mathrm{M}$ $\mathrm{C}_{2} \mathrm{H}_{5} \mathrm{OH}$. (Supplementary Materials)

\section{References}

[1] E. Antolini, "Formation of carbon-supported PtM alloys for low temperature fuel cells: a review," Materials Chemistry and Physics, vol. 78, no. 3, pp. 563-573, 2003.

[2] H. Liu, C. Song, L. Zhang, J. Zhang, H. Wang, and D. P. Wilkinson, "A review of anode catalysis in the direct methanol fuel cell," Journal of Power Sources, vol. 155, no. 2, pp. 95-110, 2006.

[3] C. Bianchini and P. K. Shen, "Palladium-based electrocatalysts for alcohol oxidation in half cells and in direct alcohol fuel cells," Chemical Reviews, vol. 109, no. 9, pp. 4183-4206, 2009.

[4] C. Wen, Y. Wei, D. Tang, B. Sa, T. Zhang, and C. Chen, "Improving the electrocatalytic properties of Pd-based catalyst for direct alcohol fuel cells: effect of solid solution," Scientific Reports, vol. 7, no. 1, pp. 1-11, 2017.

[5] S.-W. Xie, S. Chen, Z.-Q. Liu, and C.-W. Xu, "Comparison of alcohol electrooxidation on $\mathrm{Pt}$ and $\mathrm{Pd}$ electrodes in alkaline medium," International Journal of Electrochemical Science, vol. 6, pp. 882-888, 2011.

[6] R. Kannan, A. R. Kim, and D. J. Yoo, "Enhanced electrooxidation of methanol, ethylene glycol, glycerol, and xylitol over a polypyrrole/manganese oxyhydroxide/palladium nanocomposite electrode," Journal of Applied Electrochemistry, vol. 44, no. 8, pp. 893-902, 2014.

[7] A.-L. Wang, X.-J. He, X.-F. Lu, H. Xu, Y.-X. Tong, and G.-R. Li, "Palladium-cobalt nanotube Arrays supported on carbon fiber cloth as high-performance flexible electrocatalysts for ethanol oxidation," Angewandte Chemie International Edition, vol. 54, no. 12, pp. 3669-3673, 2015.
[8] B. Sen, S. Kuzu, E. Demir, S. Akocak, and F. Sen, "Monodisperse palladium-nickel alloy nanoparticles assembled on graphene oxide with the high catalytic activity and reusability in the dehydrogenation of dimethylamine-borane," International Journal of Hydrogen Energy, vol. 42, no. 36, pp. 23276-23283, 2017.

[9] H. Zhao, J. Yang, L. Li, H. Li, J. Wang, and Y. Zhang, "Effect of over-oxidation treatment of $\mathrm{Pt}-\mathrm{Co} /$ polypyrrole-carbon nanotube catalysts on methanol oxidation," International Journal of Hydrogen Energy, vol. 34, no. 9, pp. 3908-3914, 2009.

[10] R. Carrera-Cerritos, C. Salazar-Hernandez, I. R. GalindoEsquivel, and R. Fuentes-Ramirez, "Effect of the reduction temperature of PdAg nanoparticles during the polyol process in the ethanol electrooxidation reaction," Journal of Nanomaterials, vol. 2018, Article ID 9451421, 9 pages, 2018.

[11] R. N. Singh, A. Singh, and Anindita, "Electrocatalytic activity of binary and ternary composite films of Pd, MWCNT and Ni, part II: methanol electrooxidation in $1 \mathrm{M} \mathrm{KOH}$," International Journal of Hydrogen Energy, vol. 34, no. 4, pp. 20522057, 2009.

[12] Z. Zhang, C. Zhang, J. Sun, T. Kou, and C. Zhao, "Ultrafine nanoporous $\mathrm{Cu}-\mathrm{Pd}$ alloys with superior catalytic activities towards electro-oxidation of methanol and ethanol in alkaline media," RSC Advances, vol. 2, no. 31, p. 11820, 2012.

[13] K. Ramachandran, M. Vinothkannan, A. R. Kim, S. Ramakrishnan, and D. J. Yoo, "Ultrafine bimetallic alloy supported on nitrogen doped reduced graphene oxide toward liquid-fuel oxidation: profile of improved performance and extended durability," International Journal of Hydrogen Energy, vol. 44, no. 39, pp. 21769-21780, 2019.

[14] R. Arukula, M. Vinothkannan, A. R. Kim, and D. J. Yoo, "Cumulative effect of bimetallic alloy, conductive polymer and graphene toward electrooxidation of methanol: an efficient anode catalyst for direct methanol fuel cells," Journal of Alloys and Compounds, vol. 771, pp. 477-488, 2019.

[15] P. Song, L. Liu, A.-J. Wang, X. Zhang, S.-Y. Zhou, and J.-J. Feng, "One-pot synthesis of platinum-palladium-cobalt alloyed nanoflowers with enhanced electrocatalytic activity for ethylene glycol oxidation," Electrochimica Acta, vol. 164, pp. 323-329, 2015.

[16] J. Mathiyarasu and K. L. N. Phani, "Carbon-supported palladium-cobalt-noble metal $(\mathrm{Au}, \mathrm{Ag}, \mathrm{Pt})$ nanocatalysts as methanol tolerant oxygen-reduction cathode materials in DMFCs," Journal of The Electrochemical Society, vol. 154, no. 11, pp. B1100-B1105, 2007.

[17] Y. Ma, Y. Li, P. Li, and Q. Li, "Facile one-pot synthesis of carbon supported PdCuCo nanoalloy catalysts for formic acid electrooxidation," International Journal of Electrochemical Science, vol. 14, pp. 743-754, 2019.

[18] X. Zhang, Y.-C. Zhang, J.-W. Zhang, and B. Zhang, "Anchoring ternary CuFePd nanocatalysts on reduced graphene oxide to improve the electrocatalytic activity for the methanol oxidation reaction," RSC Advances, vol. 5, no. 123, pp. 101563-101568, 2015.

[19] S. Hu, F. Munoz, J. Noborikawa, J. Haan, L. Scudiero, and S. Ha, "Carbon supported Pd-based bimetallic and trimetallic catalyst for formic acid electrochemical oxidation," Applied Catalysis B: Environmental, vol. 180, pp. 758-765, 2016.

[20] Q. Dong, Y. Zhao, X. Han, Y. Wang, M. Liu, and Y. Li, "Pd/Cu bimetallic nanoparticles supported on graphene nanosheets: facile synthesis and application as novel electrocatalyst for ethanol oxidation in alkaline media," International Journal of Hydrogen Energy, vol. 39, no. 27, pp. 14669-14679, 2014. 
[21] Z. Yin, W. Zhou, Y. Gao, D. Ma, C. J. Kiely, and X. Bao, "Supported $\mathrm{Pd}-\mathrm{Cu}$ bimetallic nanoparticles that have high activity for the electrochemical oxidation of methanol," Chemistry-A European Journal, vol. 18, no. 16, pp. 48874893, 2012.

[22] B. Huang, L. Chen, Y. Wang, L. Ouyang, and J. Ye, "Paragenesis of palladium-cobalt nanoparticle in nitrogen-rich carbon nanotubes as a bifunctional electrocatalyst for hydrogen-evolution reaction and oxygen-reduction reaction," Chemistry-A European Journal, vol. 23, no. 32, pp. 77107718, 2017.

[23] Y. Wang, X. Wang, and C. M. Li, "Electrocatalysis of Pd-Co supported on carbon black or ball-milled carbon nanotubes towards methanol oxidation in alkaline media," Applied Catalysis B: Environmental, vol. 99, no. 1-2, pp. 229-234, 2010.

[24] Z. Zhang, L. Xin, K. Sun, and W. Li, "Pd-Ni electrocatalysts for efficient ethanol oxidation reaction in alkaline electrolyte," International Journal of Hydrogen Energy, vol. 36, no. 20, pp. 12686-12697, 2011.

[25] Y. Wang, F.-F. Shi, Y.-Y. Yang, and W.-B. Cai, "Carbon supported Pd-Ni-P nanoalloy as an efficient catalyst for ethanol electro-oxidation in alkaline media," Journal of Power Sources, vol. 243, pp. 369-373, 2013.

[26] X. Liang, B. Liu, J. Zhang, S. Lu, and Z. Zhuang, “Ternary $\mathrm{Pd}-\mathrm{Ni}-\mathrm{P}$ hybrid electrocatalysts derived from $\mathrm{Pd}-\mathrm{Ni}$ coreshell nanoparticles with enhanced formic acid oxidation activity," Chemical Communications, vol. 52, no. 74, pp. 11143-11146, 2016, http://agris.fao.org/agris-search/ search.do? recordID $=$ US201900345360.

[27] H. Rostami, T. Abdollahi, P. Mehdipour, A. A. Rostami, and D. Farmanzadeh, "Effect of $\mathrm{Ni}$ addition on electrocatalytic activity of $\mathrm{PdCu}$ catalysts for ethanol electrooxidation: an experimental and theoretical study," International Journal of Hydrogen Energy, vol. 42, no. 39, pp. 24713-24725, 2017.

[28] Y. Huang, Y. Guo, and Y. Wang, "Ethylene glycol electrooxidation on core-shell $\mathrm{PdCuBi}$ nanoparticles fabricated via substitution and self-adsorption processes," Journal of Power Sources, vol. 249, pp. 9-12, 2014.

[29] P. Kim, J. B. Joo, W. Kim, J. Kim, I. K. Song, and J. Yi, " $\mathrm{NaBH}_{4}$-assisted ethylene glycol reduction for preparation of carbon-supported Pt catalyst for methanol electro-oxidation," Journal of Power Sources, vol. 160, no. 2, pp. 987-990, 2006.

[30] Z. Yan, M. Wang, J. Liu, R. Liu, and J. Zhao, "Glycerol-stabilized $\mathrm{NaBH}_{4}$ reduction at room-temperature for the synthesis of a carbon-supported PtxFe alloy with superior oxygen reduction activity for a microbial fuel cell," Electrochimica Acta, vol. 141, pp. 331-339, 2014.

[31] A. Chen and C. Ostrom, "Palladium-based nanomaterials: synthesis and electrochemical applications," Chemical Reviews, vol. 115, no. 21, pp. 11999-12044, 2015.

[32] A. L. Bugaev, V. A. Polyakov, A. A. Tereshchenko et al., "Chemical synthesis and characterization of $\mathrm{Pd} / \mathrm{SiO}_{2}$ : the effect of chemical reagent," Metals, vol. 8, no. 2, p. 135, 2018.

[33] R. M. Modibedi, T. Masombuka, and M. K. Mathe, "Carbon supported Pd-Sn and Pd-Ru-Sn nanocatalysts for ethanol electro-oxidation in alkaline medium," International Journal of Hydrogen Energy, vol. 36, no. 8, pp. 4664-4672, 2011.

[34] B. R. Cuenya, "Synthesis and catalytic properties of metal nanoparticles: size, shape, support, composition, and oxidation state effects," Thin Solid Films, vol. 518, no. 12, pp. 3127-3150, 2010.

[35] F. Liao, T. W. B. Lo, and S. C. E. Tsang, "Recent developments in palladium-based bimetallic catalysts," ChemCatChem, vol. 7, no. 14, pp. 1998-2014, 2015.
[36] R. Mancharan and J. B. Goodenough, "Methanol oxidation in acid on ordered NiTi," Journal of Materials Chemistry, vol. 2, no. 8, pp. 875-887, 1992.

[37] J. Huang, Z. Liu, C. He, and L. M. Gan, "Synthesis of PtRu nanoparticles from the hydrosilylation reaction and application as catalyst for direct methanol fuel cell," The Journal of Physical Chemistry B, vol. 109, no. 35, pp. 16644-16649, 2005.

[38] J. Liu, J. Ye, C. Xu, S. P. Jiang, and Y. Tong, "Kinetics of ethanol electrooxidation at Pd electrodeposited on Ti," Electrochemistry Communications, vol. 9, no. 9, pp. 23342339, 2007.

[39] M.-W. Xu, G.-Y. Gao, W.-J. Zhou, K.-F. Zhang, and H.-L. Li, "Novel $\mathrm{Pd} / \beta-\mathrm{MnO}_{2}$ nanotubes composites as catalysts for methanol oxidation in alkaline solution," Journal of Power Sources, vol. 175, no. 1, pp. 217-220, 2008.

[40] Y. Wang, Y. Zhao, J. Yin, M. Liu, Q. Dong, and Y. Su, "Synthesis and electrocatalytic alcohol oxidation performance of Pd-Co bimetallic nanoparticles supported on graphene," International Journal of Hydrogen Energy, vol. 39, no. 3, pp. 1325-1335, 2014.

[41] Y.-H. Qin, H.-H. Yang, X.-S. Zhang, P. Li, and C.-A. Ma, "Effect of carbon nanofibers microstructure on electrocatalytic activities of Pd electrocatalysts for ethanol oxidation in alkaline medium," International Journal of Hydrogen Energy, vol. 35, no. 15, pp. 7667-7674, 2010

[42] Y. Zhao, L. Zhan, J. Tian, S. Nie, and Z. Ning, "Enhanced electrocatalytic oxidation of methanol on Pd/polypyrrolegraphene in alkaline medium," Electrochimica Acta, vol. 56, no. 5, pp. 1967-1972, 2011.

[43] Y. Wang, Z. M. Sheng, H. Yang, S. P. Jiang, and C. M. Li, "Electrocatalysis of carbon black- or activated carbon nanotubes-supported Pd-Ag towards methanol oxidation in alkaline media," International Journal of Hydrogen Energy, vol. 35, no. 19, pp. 10087-10093, 2010.

[44] Y. Zhao, X. Yang, J. Tian, F. Wang, and L. Zhan, "Methanol electro-oxidation on Ni@Pd core-shell nanoparticles supported on multi-walled carbon nanotubes in alkaline media," International Journal of Hydrogen Energy, vol. 35, no. 8, pp. 3249-3257, 2010. 